\title{
Influence of nasal obstruction on auto-CPAP behaviour during sleep in sleep apnoea/hypopnoea syndrome
}

\author{
Chantal Lafond, Frédéric Sériès
}

\begin{abstract}
Background-Auto-CPAP machines have been developed to adapt automatically the positive pressure level to the required needs. The auto-CPAP response to transient nasal obstruction was tested during sleep in patients with sleep apnoeal hypopnoea syndrome (SAHS).

Methods-Nasal obstruction was induced by local instillation of histamine. Fourteen nasal challenges were performed on eight patients, seven while the patients were on the "Morphée plus" apparatus and the other seven with the patients on the "Horizon" machine.

Results-Nasal resistance increased initially by a mean (SD) of $166(66) \%$ during the trials with the "Morphée plus" and by 118 (44)\% with the "Horizon" machine. The increase in nasal resistance was always accompanied by flow limitation with one exception. Mask pressure initially decreased to the minimal permitted value as nasal resistance increased with the "Morphée plus" device. A late increase of the positive pressure level occurred sometimes. Mask pressure did not change with increasing nasal resistance when the "Horizon" device was used.

Conclusion-Neither the "Morphée plus" nor the "Horizon" device abolished flow limited breaths and resulting sleep fragmentation. We conclude that, despite the different algorithm of pressure changes, these auto-CPAP machines do not adequately respond to an acute increase in nasal resistance.

(Thorax 1998;53:780-783)
\end{abstract}

Keywords: sleep apnoea/hypopnoea syndrome; autoCPAP; nasal resistance

Unité de Recherche, Centre de

Pneumologie, Hôpital Laval, Université Laval, 2725 Chemin Sainte-Foy, Québec, Canada G1V 4G5

C Lafond

F Sériès

Correspondence to: Dr F Sériès.

Received 22 August 1997 Returned to authors 13 January 1998

Revised version received

6 March 1998

Accepted for publication

24 April 1998 adequately to nasal obstruction. The aim of this study was to evaluate the behaviour of two different auto-CPAP machines during a histamine induced increase in nasal resistance in sleeping patients with SAHS.

\section{Methods}

Eight male patients of mean (SD) age 53 (9) years and body mass index $34(6) \mathrm{kg} / \mathrm{m}^{2}$ using nasal CPAP at home (effective positive pressure (Peff) 9 (1) $\mathrm{cm} \mathrm{H}_{2} \mathrm{O}$ ) for SAHS were recruited. The clinical diagnosis of SAHS had been previously confirmed by standard polysomnography (baseline apnoea/hypopnoea index $53(26) / \mathrm{h})$. The protocol was accepted by our institution review board and written informed consent was obtained from all subjects.

Surface electroencephalographic electrodes (C3-A2 and C3-O1), electro-oculograms and submental electrodes were used to stage sleep. Following local anaesthesia ( $0.5 \mathrm{ml}$ of $2 \%$ viscous lidocaine in both nostrils) an oesophageal balloon and a plastic nasal catheter were introduced into each nostril. The nasal low bias flow catheter was placed $7-8 \mathrm{~cm}$ from the nares. ${ }^{2}$ Two thin plastic tubes of internal diameter $0.38 \mathrm{~mm}$ were introduced into each nostril 1.5 $\mathrm{cm}$ from the nares for histamine instillation (see below). The nasal mask was connected to a pneumotachograph $\left(0.343 \mathrm{l} / \mathrm{s} / \mathrm{mm} \quad \mathrm{H}_{2} \mathrm{O}\right.$, Statham Type 18518) connected to a nonrebreathing valve and to the hose of the auto-CPAP machine. The auto-CPAP devices used were the "Morphée Plus" and the "Horizon". These machines were selected because of their different operating systems and their availability for home use. The pressure adaptation of the "Morphée Plus" apparatus is regulated by a constant feedback analysis of the breath by breath changes in the compressor's speed. ${ }^{3}$ The pressure adaptation of the "Horizon" is regulated by analysis of the inspiratory flow with an integrated pneumotachograph. ${ }^{4}$ Both machines were allowed the same intervals of pressure changes (Peff +3 and $-4 \mathrm{~cm} \mathrm{H}_{2} \mathrm{O}$ ).

Each patient was randomly allocated to one of the two auto-CPAP machines, which was settled at Peff on a constant delivery mode. Premedication with oral diazepam $0.15 \mathrm{mg} / \mathrm{kg}$ was given to two patients. All measurements were made in stage 2 sleep. Following nasal challenge with histamine $(0.05-0.1 \mathrm{ml}$ histamine $2 \mathrm{mg} / \mathrm{ml}$ gently pushed through the catheter in each nostril) the CPAP machine was switched to the automatic mode. In the absence of change in nasal resistance subse- 

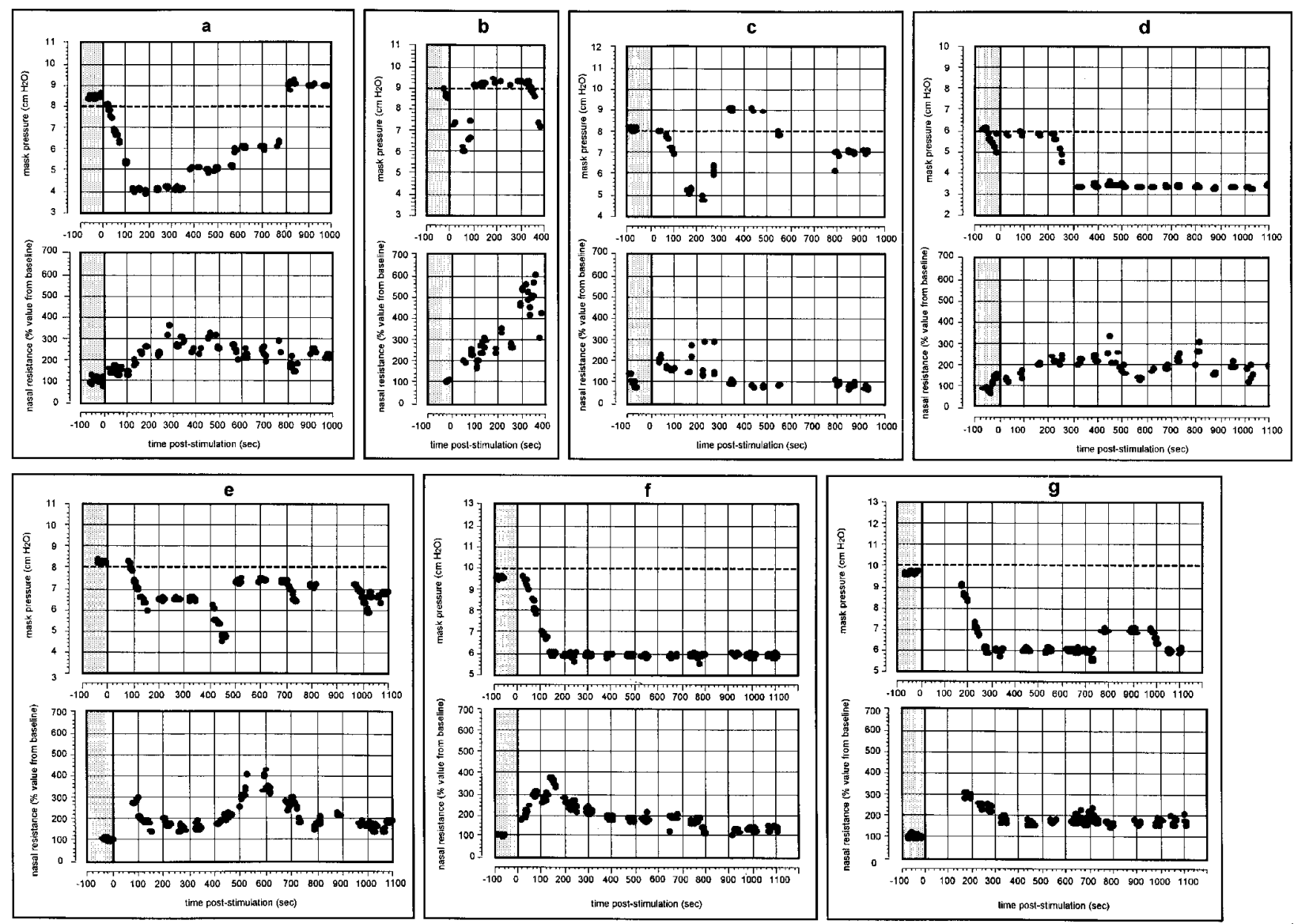

Figure 1 Individual values of simultaneous changes in mask pressure and nasal resistance over time following nasal challenge with the "Morphée plus" machine. The stippled zone represents baseline values recorded within the two minute period preceding nasal challenge. The horizontal dashed line corresponds to the reference pressure level.

quent nasal challenges were repeated by doubling histamine concentrations up to $16 \mathrm{mg} / \mathrm{ml}$.

For at least two minutes before and up to 20 minutes after nasal challenge we analysed: (1) nasal resistance at isoflow $(200 \mathrm{ml} / \mathrm{s}),(2)$ mask pressure (Pm), (3) oesophageal pressure (Poes), (4) minute ventilation, (5) flow pattern (presence or absence of flow limitation), and (6) EEG pattern (to detect arousals ${ }^{5}$ and/or awakenings ${ }^{6}$ ). Arousals provoked by nasal stimulation were excluded.

The nasal challenge was considered effective when nasal resistance increased by at least $100 \%$ from the baseline value before any change in positive pressure level. Many nasal challenges could not be retained for analysis for different reasons including: (1) sustained awakenings following nasal challenge, (2) reflex behaviours such as sneezing, (3) dramatic increases in nasal resistance resulting in mouth breathing, and (4) sudden changes in body position.

The Mann-Whitney U test was used to compare the characteristics of the patients studied with each auto-CPAP machine and the physiological responses observed with them.

\section{Results}

Fourteen studies were successfully performed, seven with the "Morphée Plus" apparatus and seven with the "Horizon". The patient charac- teristics, baseline nasal resistance, and polysomnographic data did not differ between the two groups. Three patients were studied with both machines and had two nasal challenges with the same machine during the same night (figs 1a, 1b, 2a; 1e, 2c, 2e; 1f, 2f, 2g). The increase in nasal resistance generally occurred 1-4 minutes after nasal challenge.

In the seven studies performed with the "Morphée Plus" machine nasal resistance initially increased by 166 (66)\% compared with the values before nasal challenge (95\% confidence interval (CI) 205 to 297). Individual values for the seven studies are presented in fig $1 \mathrm{a}-\mathrm{g}$. In each case Pm decreased following nasal challenge $(95 \%$ CI change in pressure from baseline -3.8 to $-2.7 \mathrm{~cm} \mathrm{H}_{2} \mathrm{O}$ ). Except in two studies (fig 1b, c) Pm decreased to the minimum permitted pressure (Peff -4 $\mathrm{cm} \mathrm{H}_{2} \mathrm{O}$ or $3 \mathrm{~cm} \mathrm{H}_{2} \mathrm{O}$ ). The decrease in $\mathrm{Pm}$ usually resulted in a further increase in nasal resistance with a maximal value for nasal resistance of 346 (97)\% from baseline (95\% CI 255 to 392). Episodes of flow limitation were observed in each study with a decrease in ventilation of 14 (10)\% (95\% CI 76.1 to 90.4$)$. Arousals were noted during each study. In three patients $\mathrm{Pm}$ re-increased following the initial pressure decrease (fig $1 \mathrm{a}-\mathrm{c}$ ). This re-increase in $\mathrm{Pm}$ exceeded the initial $\mathrm{Pm}$ value by only $0.3(0.1) \mathrm{cm} \mathrm{H}_{2} \mathrm{O}$. One study (fig 1b) 

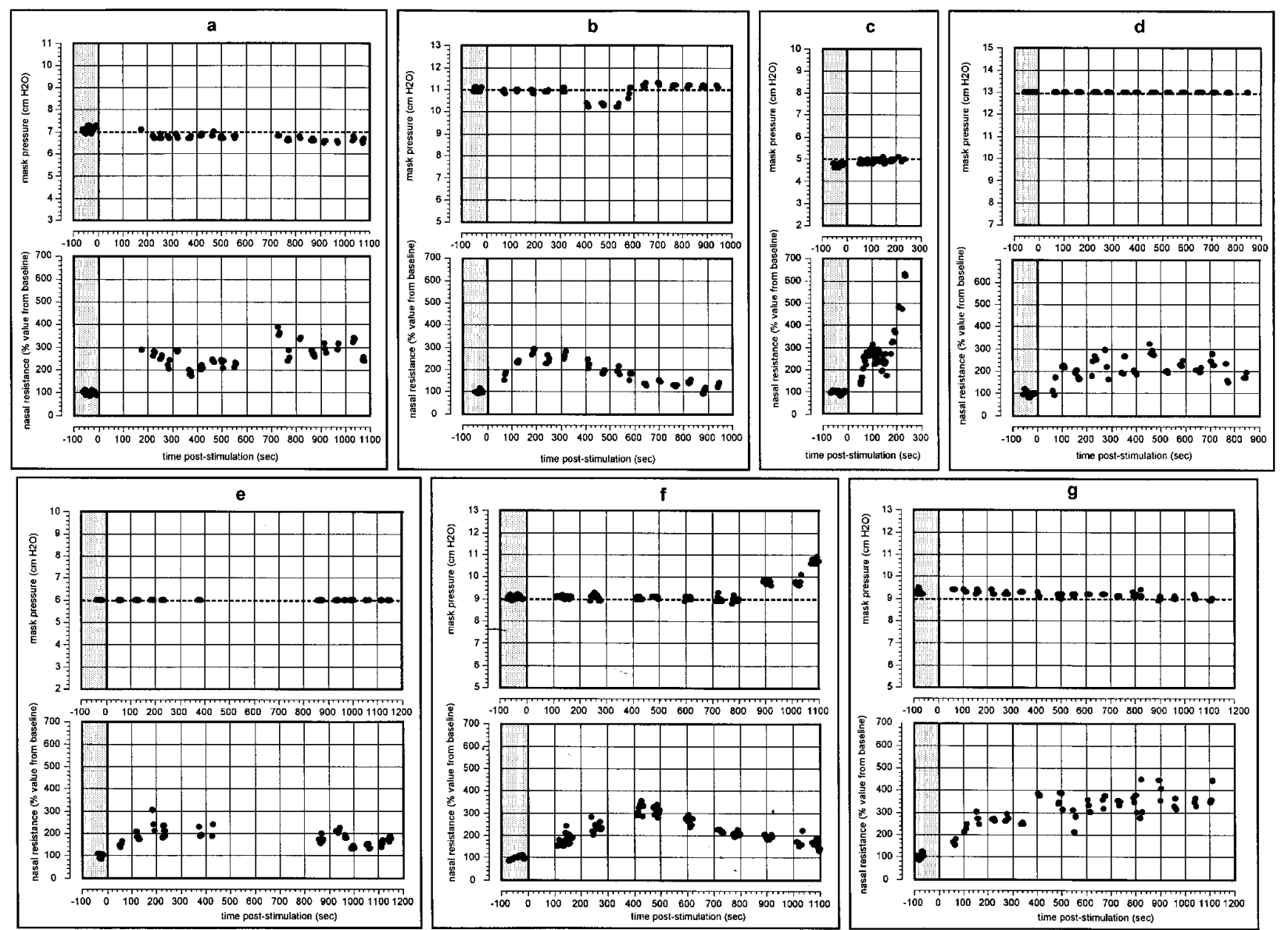

Figure 2 Individual values of simultaneous changes in mask pressure and nasal resistance over time following nasal challenge with the "Horizon" machine. Results are presented in the same way as in fig 1.

was terminated by the awakening of the patient because of a $500 \%$ increase in nasal resistance.

During the studies performed with the "Horizon" machine nasal resistance initially increased by 118 (44)\% (95\% CI 176 to 239 ). Individual nasal resistance and Pm responses are presented in fig $2 \mathrm{a}-\mathrm{g}$. In all but one study $\mathrm{Pm}$ did not change following nasal challenge; in the one exception (fig 2f) an increase of $2 \mathrm{~cm}$ $\mathrm{H}_{2} \mathrm{O}$ occurred. Episodes of flow limitation were observed in six of the seven studies. The maximal value of nasal resistance after challenge was $260(58) \%$, (95\% CI 206 to 287). Ventilation increased slightly by a mean value of $6(17) \%$ (95\% CI 90 to 113). Recurrent arousals were noted in six out of seven trials. The subject who had no arousal had no flow limitation (fig $2 b$ ). One study (fig 2c) was terminated by awakening the patient because of a $550 \%$ increase in nasal resistance.

There was no significant difference in changes in nasal resistance after challenge between the "Morphée plus" and "Horizon" studies.

\section{Discussion}

Following histamine induced increase in nasal resistance the "Morphée plus" machine invariably allowed an initial paradoxical decrease in Pm before being followed on occasion by a late re-increase in Pm. This was not sufficient to abolish episodes of flow limitation. The "Mor- phée plus" machine did not take into account episodes of stable flow limitation before changing the Pm level. In the same circumstances the "Horizon" kept the Pm at a constant level even if recurrent episodes of flow limitation occurred for a long time, suggesting that, with the built-in thresholds, the "Horizon" is slowly adaptive and not designed to prevent flow limitation.

The increase in nasal resistance produced in our experiment was acute and might not be totally similar to nasal obstruction reported by patients using CPAP on a regular basis. However, we believe that this model is useful for evaluating the capacity of these machines to abolish episodes of flow limitation and the resulting sleep fragmentation.

In conclusion, despite their different algorithms, neither the "Morphée Plus" nor the "Horizon" machines appear to respond adequately to an acute increase in nasal resistance. Further studies are required to determine whether auto-CPAP machines which respond to flow limitation have a better adapted pressure response.

This study was supported by the "Association Pulmonaire du Québec".

1 Sullivan CE, Berthon-Jones M, Issa FG, et al. Reversal of obstructive sleep apnoea by continuous positive airway obstructive sleep apnoea by continuous positive airway

2 Hudgel D, Hendricks C, Hamilton H. Characteristics of the upper airway pressure-flow relationship during sleep. $\mathcal{f}$ Appl Physiol 1988;64:1930-5. 
3 Sériès F,Marc I. Efficacy of automatic continuous positive airway pressure therapy that uses an estimated required pressure in the treatment of the obstructive sleep apnea syndrome. Ann Intern Med 1997; 127:588-95.

4 Scharf M, Brannen D, McDannold M, et al. Computerized adjustable versus fixed NCPAP treatment of obstructive sleep apnea. Sleep 1996;19:491-6.
5 Americal Sleep Disorders Association. EEG arousals: scoring rules and examples. Sleep 1992;15:174-83.

6 Rechtschaffen A, Kales A. A manual of standardized terminology, techniques and snoring system for sleep stages of human subjects. Public Health Service, Washington DC, NIH Publication No. 204, 1968. 